\title{
The Effect of Electronic Educational Assessment Environment (Navigation and Content) on Students' Intention to use MOBILE BASED ASSESSMENT from Motivational Perspective View
}

\author{
Ali Mamduh Alrfooh ${ }^{1}$, Muhammad Modi Lakulu ${ }^{1, *}$ ( corresponding Author) \\ ${ }^{1}$ Department of Computer, and Information Technology Tafila Technical university, amgma78@ttu.edu.jo \\ ${ }^{2}$ Department of Computing, Sultan Idris Education University, Malaysia,.modi@ fskik.upsi.edu.my
}

\begin{abstract}
Mobile based assessment (MBA) specifically in the context of mobile learning is still in its infancy. Many previous studies had addressed the influencing factors of user acceptance and intention to use MBA. In order to adopt MBA in an educational environment, the influencing factors to student intention need to be investigated. Hence, this current study attempts to determine the impact of the factors related to internal assessment environment on the tertiarylevel students' intent to use MBA from the standpoint of the motivation factors. A total of 90 mathematics and computer science undergraduates participated in a survey on the adoption of MBA after a real experiment of mobile based assessment. Data analysis used the structural equation modeling (SEM). The findings reveal that the students' intention to adopt MBA can be predicted and explained by several key motivational drivers i.e. Usefulness, Ease of Use and Enjoyment. Based on the findings, motivation to learn, educational assessment content, and the navigation system design of MBAs can be enhanced by satisfying the three aforementioned motivational factors.
\end{abstract}

Key words: Mobile-based assessment, Educational Technology Acceptance, Motivational Perspective, Jordan

\section{INTRODUCTION}

On top of the paper-based assessment (PBA) and computerbased assessment (CBA), MBA has become highly significant as it can be used anytime, anywhere. MBA can solve many issues related to the educational assessment conducted by PBA and CBA for example the examinations which hold outside the campus such as examinations in scientific trips, and the in medical clinics are immediate assessments which is need available assessment tool in realtime. However, the emergence of MBA recently, introduces, it mean the possibility of conducting the assessment activities based on mobile technology [1]. This process gives an advantage to teachers and students to do the assessment process anywhere and anytime. Teachers can $\log$ in and check assessment progress and enable students to conduct assessment activities without restrictions on time and place [2].

MBA can be used as an alternative tool of CBA, PBA in a pure mobilized curriculum, and a blended learning environment, and it can support different types of assessment such as self-assessment, peer assessment, game assessment [3]. It can also support different mechanisms of assessment such as summative assessment and formative assessments [4]. MBA is applicable in various educational settings in formal education where the assessment process is conducted within schools and universities, and informal education where the assessment process is conducted within museums, science centers and science trips [5]. Pedagogically, MBA can support student-center learning, where students are the focal point of learning via supporting personalization and social interactivity [6].

Although there have been many previous studies on MBA which had provided empirical evidence of its positive impact on students' performance [12, 13, 14], the driving factors for MBA acceptance have not received much research focus [7]. For this reason, this paper aims to present and investigate the most influential factors that enable the students to accept MBA. This paper is divided into several sections i.e. Section 2 briefly explains the technology acceptance model (TAM), and MBA, the research questions and research objectives; Section 3 presents the proposed research model; Section 4 explains the research methodology; Section 5 details the analysis of data, and lastly Section 6 discusses the study limitations, recommendations and conclusions.

2 TECHNOLOGY ACCEPTANCE MODEL (TAM) AND NATURE OF MBA

The well-established TAM seeks to determine users' level of acceptance and actual information technology and information system usage [8, 61, 62]. TAM is an effective framework for studying mobile learning acceptance among students $[9,10,55,56]$. It indicates that intention to use is directly determined by learners' attitude towards usage and perceived usefulness, the indirect effect of perceived usefulness and perceived ease of use, as well as other external variables $[8,10,57,58]$. This model basically predicts the extrinsic factors that drive users' intention to adopt the technology (i.e. perceived usefulness and perceived ease of use). TAM is a successful predicting model with utilitarian systems as it mainly focuses on extrinsic motivations (e.g. perceived usefulness) as well as intrinsic factors (e.g. perceived enjoyment). Both factors should be taken into consideration when investigating learners' intent to use mobile learning [11]. The MBA is a utilitarian-based system where the student needs to get good grades to pass 
the course, but at the same time it is hedonistic by nature whereby the student has the liberty to take the exam based on his/her preference in terms of time and place [3]. Hence, this study proposes that the intent to use MBA should be investigated from both extrinsic and intrinsic motivational standpoints, on top of taking into account the effect of electronic educational assessment environment (navigation and content) as the external motivation factors.

The research seeks to answer the following questions:

Q1 Does student's usefulness, student's ease of use, and student's enjoyment influence student's intentions to adopt mobile based assessment?

Q2: Does perceived usefulness mediate the correlation between perceived ease of use and the intention to use MBA?

Q3: To what extent the assessment content, navigation system of assessment environment via mobile device affects the student's usefulness, enjoyment, and ease of use?

Q4: Does the assessment content of MBA correlate with navigation of MBA?

Below are the research objectives in this study:

1.To investigate the influence of student's usefulness, enjoyment and ease of use on students' intentions to use mobile based assessment.

2.To determine the relationship between ease of use of MBA and usefulness of MBA.

3.To examine the influence of mobile assessment navigation, and content on ease of use, usefulness, and enjoyment.

4.To examine the correlation between content of Mobile Assessment and navigation.

\section{MODEL AND HYPOTHESIS DEVELOPMENT}

The development of the proposed research model (see Figure 1) is presented in this section. The TAM was chosen as the primary research model due to several reasons. Firstly, it is the most appropriate model for investigating mobile learning acceptance $[15,59,60]$. Secondly, the TAM provides a $77 \%$ increase in explaining

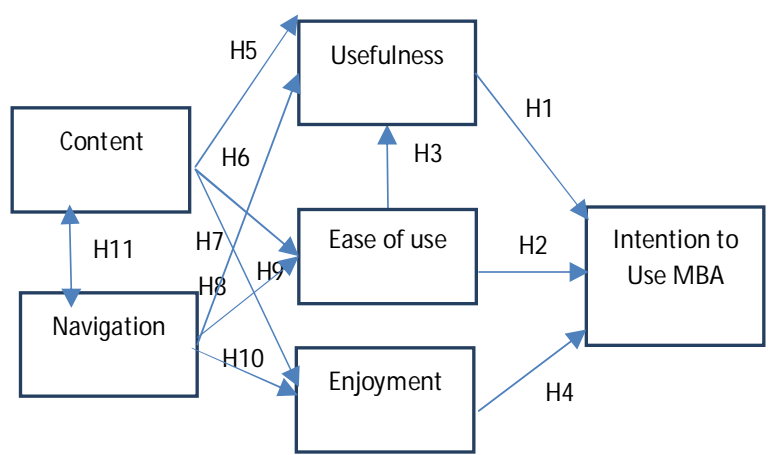

Figure 1: Hypothesis Model For Acceptance the MBA

the variance of behavioural intention whereas other models such as UTAUT and TRA only explained a $40 \%$ variance [16] indicating that TAM is a more compelling model in explaining technology adoption as compared to other models [17]. Thirdly, TAM has been widely used as a theoretical foundation in various research models in different contexts of information systems [18, 19].

Hence, the use of TAM in this study is justifiable due to its proven applicability. Therefore, this study extended, to test the effects of external predictor factors related to eassessment environment (e.g. content of assessment, and navigation system of assessment) on both the extrinsic motivation factors (e.g. Usefulness, and Ease of Use), and intrinsic motivation factors (e.g. Enjoyment) which are considered as direct influencing factors on the intention to adopt MBA. For that purpose, the researcher has developed a model for MBA acceptance as illustrated in Figure 1, followed by eleven hypotheses.

\section{Usefulness (USF) \& Ease of Use (EoU)}

The primary drivers of technology acceptance in TAM are usefulness and ease of use. Davis (1989) defined usefulness as the extent of one's belief that adopting a certain system will improve his/her work performance; meanwhile, ease of use is defined as the extent of an individual's belief that the use of a certain system does not take much physical and mental effort [8]. Past studies that had extended TAM indicated that the two factors i.e. Ease of Use and Usefulness are highly significant in determining information technology acceptance $[20,21,22,23,24,25,26,27]$. According to Davis et al. (1992) and Van der Heijden (2004), both factors directly and strongly influence users' intention to use information technologies. Usually, users tend to use systems that they perceive as useful and easy to use.

Moreover, Davis (1989) and Van der Heijden (2004) indicated that Usefulness mediates the correlation between Ease of Use and the Intention to Use a certain information system; previous studies found that Ease of Use positively affects the Perceived Usefulness of a new technology [28, 25). Also, the investigations on m-learning acceptance found that Ease of Use positively affects Perceived Usefulness [29, $30,31,32]$. In addition, a positive effect was found between two variables in CBA [33]. Therefore, the researcher hypothesized that:

H1: Usefulness has a positive relationship with the intent to use MBA

$\mathrm{H} 2$ : Ease of use has a positive relationship with the intent to use MBA.

H3: Ease of use positively associated usefulness of MBA.

\section{Enjoyment (ENJ)}

In the context of using technology, Enjoyment means the sense of fun when the individual using the technology, a part of the usefulness as a result of using this technology [34]. In the context of MAB, Enjoyment means the sense of fun when the user using the mobile based assessment, a part of the usefulness as a result of using MBA. The researchers indicated to the Enjoyment factor as intrinsic motivation that has an affects the acceptance of technology [28, 25]. This factor is based on the the motivational model (MM) presented by Davis, Bagozzi and Warshaw (1992) [35]. This construct was added to TAM by Venhatesh and Bale (2008) TAM3 [35]. Bere (2014) indicated that most of the past 
investigations found Enjoyment to significantly affect mobile technology acceptance and use. Most of the previous studies in field of m-learning indicated to the important of Enjoyment as a direct influential factor on user intention [20, $21,22,23,24,25,26,27]$ especially among young adults [36]. Enjoyment is considered as an important influential factor on Intention to Use i.e. when learning activities are hedonistic in nature. Therefore, this hypothesis is developed:

H4: Enjoyment has a positive relationship with the intent to use MBA .

\section{Content (CON)}

Content refers to the contents of the course as well as the assessment questions. Terzis and Economides (2011) outlined the significance of content in e-assessment. Nikou and Economides (2017) indicated that content positively affects MBA system acceptance. When assessment questions are appropriate, easily understood, clear and understandable, the progress of learning can be enhanced and learners perceive it to be easy to use. In addition, when assessment questions are related to the syllabus and are useful for the course, learning progress can be enhanced and perceived as useful by the learners. Assessment questions that are challenging will inject a sense of fun and enjoyment among the learners. Hence, this study assumes that Content will positively affect perceived usefulness (USF), Ease of Use (EOU) and Enjoyment (ENJ) of MBA. Therefore, the researcher hypothesized that:

H5: Content has a positive relationship with the perceived usefulness of MBA.

H6: Content has a positive relationship with the perceived ease of use of MBA.

H7: Content has a positive relationship with the enjoyment of using MBA.

\section{Navigation (NAV)}

Navigation entails self-directed movements via the media entailing a non-linear search and retrieval procedure that allows the users to experience unrestricted freedom of choice and better control [37, 38]. Mobile navigation entails the process in which the users discover all the interactivity levels on their own via the content and interface screens [39]. According to Khalifa and Shen (2008), navigational efficiency can significantly determine Perceived Usefulness. Despite certain weaknesses in mobile device applications including the small screen sizes and the expectation of being easy to use [40,41), a good navigation system should make it perfectly clear to the potential users about their position in the document and their next destination [42, 39). Based on the above, if the users are allowed to self-explore while using the mobile navigation devices via the content and interface screens, then they may perceived the mobile application as useful, easy to use and enjoyable. Hence, this investigation predicts that navigation will have a positive effect on the students' perceived Usefulness (USF), Ease of Use (EOU), and Enjoyment (ENJ) of MBA. Therefore, the researcher hypothesized that:
H8: Navigation has a positive relationship with the perceived usefulness of MBA.

H9: Navigation has a positive relationship with the perceived ease of use of MBA.

H10: Navigation has a positive relationship with the enjoyment of using MBA.

H11: Navigation positively correlates with Content of MBA

\section{METHODOLOGY}

\section{Participants}

The participants were chosen from the students who enrolled in the Discrete Mathematics Course for the second semester of 2019 at Tafila Technical University Jordan. This course is compulsory for bachelor students of Mathematics and Computer Science. The course session comprised 131 students. Ninety-four students (72\%) of the population were selected as participants of the MBA experiment using their mobile devices. But the actual number of students who participated in the experiment was 90 students. Just four students were absent at the exam's sessions. The participants were Computer Science (55\%), and Mathematics (45\%) major students, Also, there were $42 \%$ male, and $58 \%$ female on the scale of gender. Participation was voluntary whilst the data was gathered in an anonymous manner. The university's approval for participation was requested and granted.

\section{Procedure}

The mobile devices entailed Wi-Fi equipped smartphones (72\% Android, 28\% iOS). The formative assessment was conducted after the lectures using the students' mobile phones to test the students' understanding of the subject. There were a total of 15 multiple choice questions with four answer options, and 11 True/False questions as shown in Figure 2. Students had to scroll to go to the subsequent question. They received feedback on their answers. The assessment took 45 minutes in total. In order to easily access the exam, the researcher created and downloaded the QR code. The mobile application's interface was kept simple to prevent any damage. Following the assessment, the learners were requested to answer the survey questionnaire i.e. to report their opinion of the assessment process. 


\begin{tabular}{|c|}
\hline Status: Active - \\
\hline Discrete Mathematics Exam \\
\hline \multirow{2}{*}{$\begin{array}{l}\text { you have } 26 \text { Question you must answer all of } \\
\text { them } \\
\text { you can use this sets } A=\{5,4,3,2\}, B=\{5,6\}, U=\{x: x € \\
z, 1<x \leq 6\} \text { to answer the questions } 13-26\end{array}$} \\
\hline \\
\hline Q1: The number $(101010) 2=(42) 10$ \\
\hline True \\
\hline False \\
\hline Q2: The number $(100) 10=(1100100) 2$ \\
\hline True \\
\hline False \\
\hline
\end{tabular}

Figure 2: Formative Exam Conducted Via Mobile Phones Design by Researchers.

\section{Instrument}

To assess the influence of the assessment content and navigation system on Perceived Usefulness, Ease of Use and Enjoyment during the MBA procedure as well as the intent to use m-assessment, we developed a research instrument adapted from past questionnaires that have been utilized and validated by previous researchers. The instrument to assess the acceptance of MBA incorporated 21 items. For the constructs of Usefulness, Ease of Use and Behavioral Intention to Use, the researcher adopted items from [8]. For the construct of Enjoyment, the researcher adopted items from [28, 24]. The items under the construct of Content were adopted from [2]. Finally, the items for navigation were adopted from [43]. Appendix A shows the list of questionnaire items. The questionnaire was designed as an electronic form on Google drive website with two sections. Section 1 focuses on demographic information such as the students' major, gender, and smartphone type. Section 2 includes the lists of items which were assessed on a 5-point Likert scale whereby $1=$ Strongly Agree and $5=$ Strongly Disagree. To guarantee that the translated version of the questionnaire stays true to the intended meaning of the original questionnaire, a standard back-translation procedure was carried out $[44,45]$. The initial survey was in English and translated into Arabic by a doctor in the English department at the Tafila Technical University. To obtain self-report feedback from the participants, they were invited to answer the electronic form questionnaire by accessing the URL (https://forms.gle/f5gVsarHEMgEDTYg6). The URL was distributed among the participants via the group's WhatsApp application.

\section{ANALYSIS AND RESULTS}

This section presents detailed data analysis undertaken in this study. This section mainly presents and summarizes the findings in both the descriptive and inferential statistical analysis. This section delineates the process involving the testing of assumptions for the structural equation model (SEM) precisely the path analysis. The SEM approach comprises the assessment of model fit for the path analysis and hypotheses testing. Before testing the assumptions, three elements must be ascertained i.e. the questionnaire's reliability, the normal distribution of the data, and the presence of ant multicollinearity issue. Three pre-tests were conducted for this purpose as detailed below.

\section{A-Reliability Test.}

The reliability of the questionnaire was ensured via a pilot test. The questionnaire was verified before being distributed to the randomly selected sample of 30 students. The statistical package for social science (SPSS) software was used for the coding and data entry. The coding technique was used to assign numbers to the items measured (Hair et al., 1998; Holmes-Smith, 2001). The constructs of the proposed model yielded acceptable levels of reliability as shown by the reliability test results in Table 1 . All the constructs' Cronbach's $\alpha$ values were greater than the 0.7 threshold value suggested by $[46,47]$.

Table 1: The Reliability Test Results for Each Construct in The MBA Model

\begin{tabular}{|l|c|}
\hline MBA constructs & Cronbach's $\boldsymbol{\alpha}$ value \\
\hline Content (CON) & 0.823 \\
\hline Navigation (NAV) & 0.866 \\
\hline Enjoyment (ENJ) & 0.808 \\
\hline Ease of use (EoU) & 0.792 \\
\hline Usefulness (USF) & 0.757 \\
\hline Intention to use (IU) & 0.898 \\
\hline
\end{tabular}

\section{B - Normality Test.}

Normality is a particularly important assumption in conducting structural equation model analysis. Normality assumption states that data distribution should be standard. A normal distribution is established when the Skewness and kurtosis values are within -1 and +1 (for Skewness) and -3 and +3 (for kurtosis) respectively (Hair et al. 2010). Violation of normality assumption can influence the results drawn from a small sample as contained in this study. With regards to the threshold values for the Skewness and Kurtosis, this study uses the principles recommended by Hair et al. (2010) that places cut-off points within the range of 2.58 to +2.58 . Table 2 shows the Skewness and kurtosis for each variable in the MBA model.

Table 2: Skewness and Kurtosis for the Variables in MBA the Model

\begin{tabular}{|l|l|l|l|}
\hline Variable & Code & Kurtosis & Skewness \\
\hline Content & CNT & .525 & -1.210 \\
\hline Navigation & NAV & -.509 & -.111 \\
\hline Ease of Use & EoU & -1.100 & -.251 \\
\hline Usefulness & UF & -.386 & -.901 \\
\hline Enjoyment & ENJ & -1.051 & .292 \\
\hline $\begin{array}{l}\text { Intention to } \\
\text { Use }\end{array}$ & ITU & -.999 & -.422 \\
\hline
\end{tabular}




\begin{tabular}{|l|l|}
\hline Number of distinct parameters to be estimated: & 17 \\
\hline Degrees of freedom $(\mathbf{2 1}-\mathbf{1 7}):$ & 4 \\
\hline
\end{tabular}

\section{2- Model Identification}

Model identification refers to enough information in a model that is required to estimate the parameters in the model. There are three cases of model identification: over-identify model, just identify model, and under-identify model. To determine the parameters in the study model, the model must be over-identified or at least Just identify but not under identify model. The value of Degrees of Freedom (DF) is a predictor of model identification. DF equals the number of moments (means, variance, and covariance) of observed variables excluding the parameters for estimation. If the DF is beyond zero, the model is over-identified. If the DF is equal to zero, the model is just-identified, and if the DF is less than zero, the model is under-identified [48]. According to the AMOS report result shown in Table 4, the number of distinct sample moments is 21 . The number of different parameters for estimation is 17 . Therefore, the degrees of freedom (DF) equals $(21-17=4)$ as we show in Table 4 . It is concluded that the study model is over-identify because the DF is greater than Zero, and it is ready for estimation.

\section{3- Model Estimation}

The model-estimate refers to the model parameters values that the model starts based on the initial values to generate covariance matrix of the observed variables. In estimating process, the question posed is, to what extent is the matrix of the covariance of the observed variables generated by the model $(\Sigma)$ compatible with the covariance matrix of the observed variables created by the data $(S)$ ? There are many methods used to estimate a model based on fitting function (F) such as maximum likelihood, square least squares, and generalized squares [48]. The parameters were estimated using the maximum likelihood technique and the default method in AMOS. The fitting function in the maximum likelihood (FML) is calculated many times until its value approaches zero [48]. Figure 5 presents the standardized estimates for the parameters of the proposed MBA model

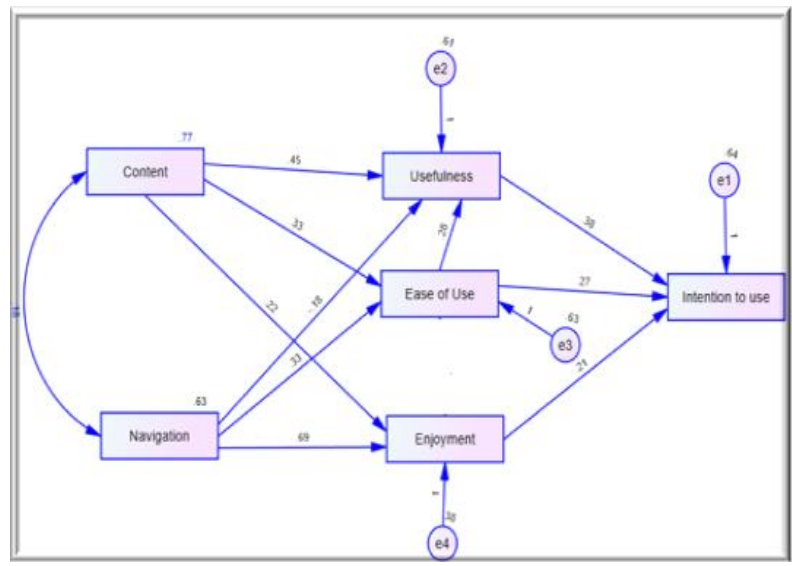

Figure 5: Standardized Estimates for the Parameters 4. Model Testing
In the model testing process, a model must fit the data to the highest degree possible. In other words, model testing is a process that aims to monitor the success of the proposed model to interpret the relationship between study variables [48]. The proposed model's fit is determined by identifying the degree of equivalence between $(\Sigma)$ and $(\mathrm{S})$. As mentioned above, this is achieved by checking the values of several criteria that used as indicators to fit a model [48]. Some of these indicators are statistical fit criteria such as Chi-square, and Probability level (P-value) of Chi-square, but it is not enough to judge for the fit of the model, duo to Chi-square is effected by the sample size, therefor others criteria are used to judge the fit of model beside Chi-square such as: Absolute fit index (e.g. Root Mean Square Error Approximation RMSEA) by this index the proposed model compare with perfect model. The relative fit index (e.g. comparative of Fit Index CFI) by this index the proposed model compares with the baseline model i.e. Goodness-of-Fit Index (e.g. Adjusted Goodness-of-Fit Index AGFI) [48].

The rule of thumb in conducting the path analysis for the measurement model and the structural model entails specifying that the AGFI must be higher than 0.9, the CFI must be larger than 0.9 , the RMSEA must be less than 0.05 , and the Chi2/df must be lower than 3 [49, 50, 51]. The overall fit indices outcomes for the measurement model were: chi2/df was 0.51 , RMSEA was 0.000 , CFI was 0.99 , and AGFI was 0.96. The results demonstrated that all the indices were well above their threshold levels (see Table 5). Hence, the proposed model fits well with the sample data.

Table 5: Fit indexes for the proposed model

\begin{tabular}{|c|c|c|}
\hline Fit indexes & Obtained & Require value \\
\hline $\mathrm{Chi}^{2} / \mathrm{DF}$ & 0.51 & $>0.50$ \\
\hline P-value & 0.68 & $>0.05$ \\
\hline CFI & 0.99 & $>0.90$ \\
\hline RMSEA & 0.00 & $<0.05$ \\
\hline AGFI & 0.96 & $>0.90$ \\
\hline \multicolumn{3}{|c|}{$\begin{array}{l}\mathrm{Ch}^{2} \text { Chi Squire, DF Degree of Freedom, P Probability level ,CFI } \\
\text { Comparative of Fit Index ,RMSEA Root Mean Squire Error } \\
\text { Approximation, AGFI Adjusted Goodness-of-Fit Index }\end{array}$} \\
\hline
\end{tabular}

The fit indexes of the hypothesized model are favorable; however, a look at the path coefficients indicated that the model needs revision. For example, the path coefficient between Navigation (NAV) and Usefulness (USF) is not significant as well. The critical ratio (CR) value did not meet the cut-of-point of 1.96 as shown in Table 6.

Table 6: Hypothesized model Path coefficients for proposed model. 


\begin{tabular}{|c|c|c|c|c|c|}
\hline 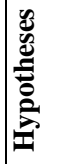 & 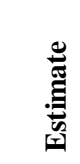 & $\frac{\dot{x}}{\dot{\sigma}}$ & نُ & 2 & 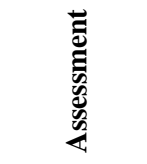 \\
\hline $\mathrm{H} 1$ & .383 & .098 & 3.898 & .000 & Supported \\
\hline $\mathrm{H} 2$ & .268 & .108 & 2.488 & .013 & Supported \\
\hline H3 & .209 & .102 & 2.044 & .041 & Supported \\
\hline $\mathrm{H} 4$ & .280 & .104 & 2.687 & .007 & Supported \\
\hline H5 & .453 & .104 & 4.367 & $* *$ & supported \\
\hline H6 & .326 & .100 & 3.270 & .001 & supported \\
\hline H7 & .223 & .081 & 2.741 & .006 & supported \\
\hline H8 & -.179 & .113 & 1.585 & .113 & $\begin{array}{l}\text { Not } \\
\text { Supported }\end{array}$ \\
\hline H9 & .328 & .110 & 2.990 & .003 & supported \\
\hline $\mathrm{H} 10$ & .688 & .089 & 7.755 & *** & supported \\
\hline H11 & .181 & .076 & 2.374 & .018 & Supported \\
\hline \multicolumn{6}{|c|}{$\begin{array}{l}\text { ***. Correlation is significant at the } 0.001 \text { level. } \\
\text { **. Correlation is significant at the } 0.01 \text { level. } \\
\text { SE. Standardized Error, CR. Critical Ratio, P Pro }\end{array}$} \\
\hline
\end{tabular}

\section{5-Model Modification}

The analysis of the path structure model shown in Table 5 does not fit properly given that it is not significant for one of the major hypotheses. Due to this poor data fit, the researchers attempt to produce a better model for both the goodness-of fit as well as path coefficient. As such, the paths that are not significant are removed from the model along with the problematic indicators. With this step, the model becomes improved. Figure 6 shows the standard estimation result of the revised model.

The full-fledged revised model is satisfactory for all the fit indexes (see Figure 6). The results show that the revised model has a generally acceptable model fit. The comparative Chi-square or Normed chi-square, in which the chi-square fit index is divided by extent of freedom $(\mathrm{CMIN} / d f)$, was valued at 0.900 , which is below the cut-off value of 3.000 (Kline, 2011). The results showed that the Root Mean Square Error of Approximation (RMSEA) $=.000$, the Comparative Fit Index $(\mathrm{CFI})=0.97$, the Root Mean Square Residual RMR = .029 , and the Adjusted Goodness-of-Fit Index (AGFI) $=$ 0.93 . These results indicate that the revised model generally fits the sample data well. Table 7 presents the summary of fit indexes of the model.

Following the determination of the model fit, further evaluations were made on the all the parameters. The ten hypotheses for the path relationships were then tested. The path coefficient results are presented in Table 8 .

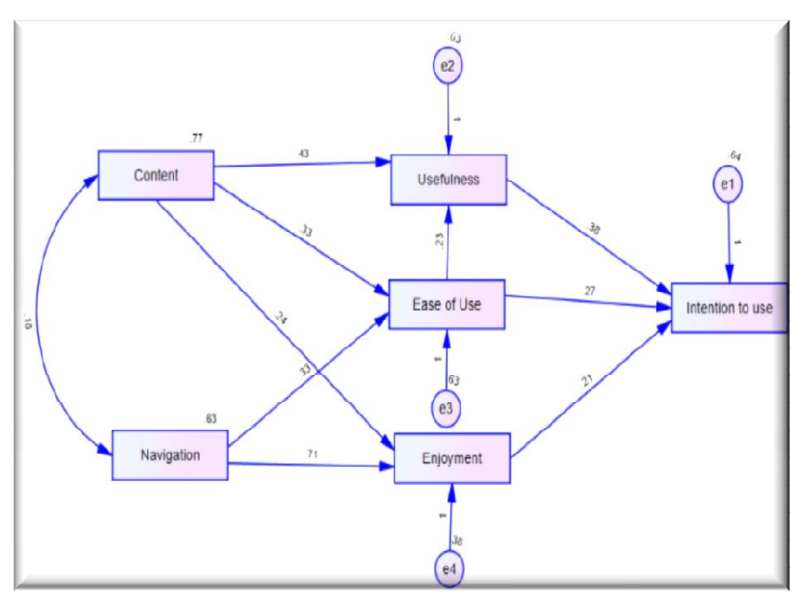

Figure 6: Standardized Estimates for the Parameters

Table 7: Fit Indexes for the Revised Model

\begin{tabular}{|l|l|l|}
\hline Fit indexes & Obtained & Require value \\
\hline Chi-square/DF & 0.9 & $>0.05$ \\
\hline P-value & 0.48 & $>0.05$ \\
\hline CFI & 0.97 & $>0.90$ \\
\hline RMSEA & 0.00 & $<0.05$ \\
\hline AGFI & 0.93 & $>0.90$ \\
\hline RMR & 0.029 & $<0.05$ \\
\hline
\end{tabular}

Table 8: Hypothesized Model Path Coefficients of the Revised Model

\begin{tabular}{|l|c|c|c|c|c|}
\hline & & & & & \\
\hline H1 & .360 & .099 & 3.868 & $* * *$ & Supported \\
\hline H2 & .244 & .108 & 2.488 & .013 & Supported \\
\hline H3 & .223 & .101 & 2.284 & .022 & Supported \\
\hline H4 & .188 & .105 & 2.549 & .011 & Supported \\
\hline H5 & .403 & .104 & 4.133 & $* * *$ & supported \\
\hline H6 & .315 & .100 & 3.270 & .001 & supported \\
\hline H7 & .237 & .077 & 3.138 & .002 & supported \\
\hline H9 & .288 & .101 & 2.284 & .022 & supported \\
\hline H10 & .628 & .085 & 8.336 & $* * *$ & supported \\
\hline H11 & .181 & .076 & 2.374 & .018 & Supported \\
\hline$* * *$. Correlation is significant at the 0.001 level \\
\hline
\end{tabular}


H1: Perceived Usefulness (USF) has a positive effect on intention to use mobile-based assessment.

Table 8 shows that C.R. and p-value of students' perceived usefulness of MBA in predicting intention to use MBA are 3.868 and 0.000 , respectively. This indicates that the possibility of achieving an absolute t-value of up to 3.86 is < 0.000 i.e. the regression weight for the students' perceived usefulness in predicting intention to use MBA is strong and significantly different than zero at a 0.000 level. Hence, H1 is proven. Additionally, the path coefficient indicated a positive relationship with a value of 0.360 , meaning that when students' perceived usefulness of MBA increases by one standard deviation, the intention to adopt MBA increases by 0.360 . In other words, Perceived Usefulness and Intention to Use MBA have a significant correlation. Perceived usefulness (USF) is a strong predictor of intention to use (ITU) with standardized beta $(\beta)$ of .360 , critical ratio C.R. (3.868) standardized error (S.E.) of .099 and p-value of 0.000 .

H2: Perceived Ease of Use (EOU) positively affects the intent to use MBA.

Table 8 shows that the CR and p-value of the students' Perceived Ease of Use of MBA in predicting the Intention to Use MBA are respectively 2.488 and 0.013 , indicating that the possibility of achieving an absolute t-value of up to 2.488 is 0.013 . Put differently, the regression weight for students' perceived ease of use in predicting intention to use MBA is strong and significantly different from zero at a 0.013 level. Therefore, $\mathrm{H} 2$ is supported. Furthermore, the path coefficient is 0.244 , indicating a positive relationship.

This suggests that when students' perceived ease of use of MBA increases by one standard deviation, the intention to use MBA increases by 0.224 .

H3: Perceived Ease of Use (EOU) has a positive effect on Perceived Usefulness (USF) of mobile-based assessment.

Table 8 shows that the CR and p-value of the students' Perceived Ease of Use of MBA in predicting the Perceived Usefulness of MBA are 2.284 and 0.022 , respectively. This indicates that the possibility of achieving an absolute t-value of up to 2.284 is 0.022 . In short, the regression weight for the students' Perceived Ease of Use in predicting the Perceived Usefulness (USF) of MBA is strong and significantly different from zero at a 0.022 level. Therefore, H3 is supported. Furthermore, the path coefficient is 0.223 , indicating a positive relationship. This suggests that when students' perceived ease of use of MBA increases by one standard deviation, Perceived Usefulness (USF) increases by 0.223 .

H4: Perceived Enjoyment (ENJ) positively affects the intent to use MBA.

Table 8 shows that the CR and p-value of the students' perceived enjoyment of MBA in determining the Intent to Use MBA are 2.549 and 0.011 , respectively. This indicates that the possibility of achieving an absolute t-value of up to 2.549 is 0.011 . Thus, the regression weight for the students' perceived enjoyment in predicting intention to use MBA is strong and significantly different than zero at a 0.011 level. Therefore, H4 is supported. Furthermore, the path coefficient is 0.188 , indicating a positive relationship. This suggests that when students' perceived enjoyment of MBA increases by one standard deviation, the intention to use MBA increases by 0.188 .

H5: Content (CON) positively affects the Perceived Usefulness (USF) of MBA.

There is a significant relationship observed between Content (CON) and Perceived Usefulness (USF) of MBA. Content $(\mathrm{CON})$ is a strong predictor of Perceived Usefulness (USF) with standardized beta $(\beta)$ of 0.403 , critical ratio CR (4.133), standardized error (SE) of 0.104 and p-value of 0.000 . Table8 shows that $\mathrm{CR}$ and $\mathrm{p}$-value Content $(\mathrm{CON})$ of MBA in predicting perceived usefulness are 4.133 and 0.000 , respectively. This indicates the possibility of achieving an absolute t-value of up to 4.133 is $<0.000$. In short, the regression weight for Content $(\mathrm{CON})$ in predicting Perceived Usefulness (USF) of MBA is strong and significantly different from zero at a 0.000 level. Therefore, H5 is supported. Furthermore, the path coefficient is 0.403 , indicating a positive relationship. This suggests that when Content (CON) of MBA increases by one standard deviation, Perceived Usefulness (USF) increases by 0.403 .

H6: Content (CON) positively affects the Perceived Ease of Use (EOU) of MBA.

There is a significant relationship observed between content $(\mathrm{CON})$ and perceived Ease of Use (EOU) of MBA. Content $(\mathrm{CON})$ is a strong determiner of Perceived Ease of Use (EOU) with standardized beta $(\beta)$ of 0.315 , critical ratio $C R$ (3.270), standardized error (SE) of 0.100 and p-value of 0.001. As shown in Table 8, CR and p-value Content (CON) of MBA in predicting Perceived Ease of Use (EOU) are 3.270 and 0.001 , respectively. This indicates that the possibility of achieving an absolute t-value of up to 3.270 is 0.001. In short, the regression weight for Content $(\mathrm{CON})$ in predicting Perceived Ease of Use (EOU) of MBA is strong and significantly different from zero at a 0.001 level. Therefore, H6 is supported. Furthermore, the path coefficient is 0.315 , indicating a positive relationship. This implies that when Content $(\mathrm{CON})$ of MBA increases by one standard deviation, Perceived Ease of Use (EOU) increases by 0.315 .

H7: Content (CON) positively affects the Perceived Enjoyment (ENJ) of MBA.

There is a significant relationship observed between content (CON) and perceived Enjoyment (ENJ) of MBA. Content $(\mathrm{CON})$ is a strong predictor of Perceived Enjoyment (ENJ) with standardized beta $(\beta)$ of 0.237 , critical ratio CR (3.138), standardized error (SE) of 0.077and p-value of 0.002. As shown in Table 1.8, CR and p-value Content (CON) of MBA in predicting perceived Enjoyment (ENJ) are 3.138 and 0.002 , respectively. This indicates that the possibility of achieving an absolute t-value of up to 3.138 is 0.002 . Hence, the regression weight for Content $(\mathrm{CON})$ in predicting Perceived Enjoyment (ENJ) of MBA is strong and significantly different from zero at a 0.002 level. Therefore, 
$\mathrm{H} 7$ is supported. Furthermore, the path coefficient is 0.237 , indicating a positive relationship. This implies that when Content (CON) of MBA increases by one standard deviation, Perceived Enjoyment (ENJ) increases by 0.237.

H9: Navigation (NVA) positively affects the Perceived Ease of Use (EOU) of MBA.

Navigation (NVA) and perceived Ease of Use (EOU) of MBA are significantly correlated. Navigation (NVA) is a strong determiner of Perceived Ease of Use (EOU) with standardized beta $(\beta)$ of 0.288 , critical ratio CR (2.284), standardized error (SE) of 0.101 and p-value of 0.022. Table 8 shows that the CR and p-value for Navigation (NVA) of MBA in predicting perceived Ease of Use (EOU) are 2.284 and 0.022 , respectively. This indicates that the possibility of achieving an absolute t-value of up to 2.284 is 0.022 . Hence, the regression weight for Navigation (NVA) in predicting Perceived Ease of Use (EOU) of MBA is strong and significantly different from zero at a 0.022 level. Therefore, H9 is supported. Furthermore, the path coefficient is 0.288 , indicating a positive relationship. This implies that when Navigation (NVA) of MBA increases by one standard deviation, Perceived Ease of Use (EOU) increases by 0.288.

H10: Navigation (NVA) positively affects the Perceived Enjoyment (ENJ) of MBA.

Table 8 shows that C.R and p-value of students' Navigation (NVA) of MBA in predicting Perceived Enjoyment (ENJ) of MBA are 8.336 and 0.000 , respectively. This indicates that the possibility of achieving an absolute t-value of up to 8.336 is $<0.000$. Hence, the regression weight for the students' Navigation (NVA) in predicting Perceived Enjoyment (ENJ) of MBA is strong and significantly different from zero at a 0.000 level. Therefore, H10 is supported. Furthermore, the path coefficient is 0.628 , indicating a positive relationship. This shows that when students' Navigation (NVA) of MBA increases by one standard deviation, Perceived Enjoyment (ENJ) of MBA increases by 0.628 .

H11: Content positively correlates with Navigation.

Content (CON) and Navigation of MBA were found to have a significant relationship. Content $(\mathrm{CON})$ correlates with Navigation (NVA) with correlation coefficient $r=0.181$, critical ratio CR (2.374), standardized error (SE) of 0.076 and p-value of 0.018 .

\section{DISCUSSION, LIMITATIONS, RECOMMENDATIONS, AND CONCLUSIONS}

\section{Discussion on the Findings and Answering the Research Questions}

Q1: Does student's usefulness, student's ease of use, and student's enjoyment influence student's intentions to adopt MBA?

From this research question, three subsequent research questions are formulated to support main research question.
1-Does Perceived Usefulness (USF) positively affect the intent to use MBA?

This research question examines the causal relationship between usefulness of MBA and students intention to use MBA. It is evaluated in H1: Perceived Usefulness (USF) positively affects the intent to use MBA. The results show that the path coefficient between these two variables is of practical importance and statistically significant. Due to this, the structural path of the model supports hypothesis one that states that perceived usefulness positively affects the intent to use MBA. The findings of the earlier studies showed that perceived usefulness is significant in determining the acceptance of m-learning among students [52]. In addition, perceived usefulness is crucial in the acceptance of information system IT [28, 24, 25].

2-Does perceived Ease of Use (EOU) positively affects the intent to use MBA?

The above research question looks into the relationship between Ease of Use and Intention to Use MBA. The correlation between Ease of Use and Intention to Use MBA is evaluated in $\mathrm{H} 2$, which states that perceived Ease of Use (EOU) positively affects the intent to use MBA. The results show that the path coefficient between these two variables is of practical importance and statistically significant. Based on this, the structural path of the model supported the $\mathrm{H} 2$ that states that perceived Ease of Use positively affects the intent to use MBA. Previous literatures with empirical evidence showed that perceived ease of use influences intentions to use MBA [24, 25]. Perceived ease of use directly determines the intent to use information system IT [28, 25].

3-Does Perceived Enjoyment (ENJ) positively affect the intent to use MBA?

This research question examines the correlation between Perceived Enjoyment and Intention to Use MBA. The correlation was tested in $\mathrm{H} 4$, which states that perceived Enjoyment (ENJ) positively affects the intent to use mobilebased assessment. The results show that path coefficient between these two variables is of practical importance and statistically significant. For this reason, the structural path of the model supports $\mathrm{H} 3$ that states that Perceived Enjoyment (ENJ) has a positive effect on the Intention to Use mobilebased assessment. Existing empirical evidence showed that perceived enjoyment influences intentions to use m-learning $[52,54]$. Studies found that enjoyment directly affects the intent to use information technology IT [53].

Q2: Does the student's usefulness, mediate the influence of student's ease of use on students' intentions to use MBA?

The research question investigates the relationship between perceived Ease of Use and perceived Usefulness of mobilebased assessment. Relationship between perceived ease of use and perceived Usefulness of MBA is tested in H3. It states that perceived Ease of Use (EOU) positively affects the perceived usefulness of mobile based assessment. The results show that the path coefficient between these two variables is of practical importance and statistically significant. Based on this, the structural path of the model 
supports the hypothesis that states that perceived ease positively affects the perceived usefulness of mobile-based assessment. Existing literature with empirical evidence showed that perceived ease of use affects the perceived usefulness of information technology acceptance $[21,22,23$, $24,25,27,28]$.

Q3: To what extent the assessment content, navigation system of assessment environment via mobile device affects the student's usefulness, enjoyment, and ease of use?

From this research question, sex subsequent research questions are formulated to support main research question.

1-Does Content of assessment (CON) positively affect the Perceived Usefulness (USF) of MBA?

The research question investigates the relationship between Content of MBA and perceived Usefulness. The relationship between Content and perceived Usefulness of MBA is tested in $\mathrm{H} 5$, which states that Content positively affects the perceived usefulness of mobile-based assessment. The results reveal that the path coefficient between these two variables is of practical importance and statistically significant. Based on this, the structural path of the model supports the hypothesis that content positively affects the perceived usefulness of MBA. This finding is in line with past researches which show that content of technology influences the perceived usefulness. When assessment questions are related to student's course and syllabus, it can improve the learning process and perceived as useful for the learners $[1,2]$.

2-Does Content assessment (CON) positively affect the Perceived Ease of Use (EOU) of mobile-based assessment?

The research question investigates the relationship between Content of MBA and perceived ease of use. The correlation between Content and perceived ease of use of MBA is tested in H6, which states that Content positively affects the perceived ease of use of MBA. The results reveal that path coefficient between these two variables is of practical importance and statistically significant. For this reason, the structural path of the model supports the hypothesis that states that content positively affects the perceived ease of use of MBA. This finding is in line with past researches, which show that content of technology influences the perceived ease of use computer-based assessment (CBA) [33]. When assessment questions are easily understood, clear, understandable, assessment can enhance learning process and is considered easy to use by the students $[1,2]$

3-Does Content of assessment (CON) positively affect the Perceived Enjoyment (ENJ) of MBA?

The research question explores the relationship between Content of MBA and perceived enjoyment. The relationship between Content and perceived enjoyment of MBA is tested in H7. This states that Content positively affects the perceived enjoyment of MBA. The results reveal that the path coefficient between these two variables is of practical importance and statistically significant. For this reason, the structural path of the model supports the hypothesis that states that content positively affects the perceived enjoyment of using MBA. This result is supported by findings of $[1,2]$ which state that when the content of assessment questions is optimally challenging, students have a sense of fun and enjoyment with assessment.

4-Does Navigation (NVA) positively affect the Perceived usefulness (USF) of MBA?

The research question explores the relationship between Navigation and perceived usefulness of MBA. The relationship between Navigation and perceived usefulness of MBA is tested in H8, which states that navigation positively affects the perceived usefulness of mobile-based assessment. The results reveal that the path coefficient between the two variables is statistically not significant. For this reason, the structural path of the model does not support the hypothesis that states that navigation positively affects the perceived usefulness of MBA. This result is not supported by the findings of [38]. Navigation flexibility via an interactive online setting determines the shoppers' perceived usefulness of the interactive media [37]. The researcher think that the important of the navigation system towered the user's usefulness does not appear in MBA, probably due to the nature of formative exam which is considered as a microlearning activity (e.g. quizzes).

5-Does Navigation (NVA) positively affect the Perceived Ease of Use (EOU) of mobile-based assessment?

The research question explores the relationship between Navigation and perceived ease of use of mobile-based assessment. The correlation between Navigation and perceived ease of use of MBA is tested in H9, which states that navigation positively affects the perceived ease of mobile-based assessment. The results reveal that the path coefficient between these two variables is of practical importance and statistically significant. For this reason, the structural path of the model supports the hypothesis which states that navigation positively affects the perceived ease of use of MBA. This result is supported by the findings of [38]. Navigation flexibility via an interactive online setting determines the shoppers' perceived ease of use of the interactive media [37, 63].

6-Does Navigation (NVA) positively affect the Perceived Enjoyment (ENJ) of using MBA?

The research question explores the relationship between Navigation and perceived enjoyment of mobile-based assessment. The relationship between Navigation and perceived enjoyment of MBA is tested in Hypothesis 10, which states that navigation positively affects the perceived enjoyment of using MBA. The results reveal that the path coefficient between these two variables is of practical importance and statistically significant. Based on this, the structural path of the model supports the hypothesis that states that navigation positively affects the perceived enjoyment of using MBA. This result is supported by the findings of [38] and [37]. The enjoyment of shoppers in using interactive media can be enhanced by improving the navigating ability in an interactive online setting [37]. 
Q4. Does navigation have a positive correlation with content?

The research question explores the relationship between Navigation and Content of mobile-based assessment. The relationship between Navigation and content of MBA is tested in $\mathrm{H} 11$, which states that navigation has a positive correlation with content of mobile-based assessment. The results reveal that the correlation coefficient $r$ between these two variables is of practical importance and statistically significant. Based on this, the correlation coefficient model supports the hypothesis that states that navigation has a positive correlation with content of MBA.

According to the standard estimation results of the revised model, which are illustrated in the estimation column in Table 1.8, the effect of the three direct influential factors on intention to use (usefulness, Ease of Use, and Enjoyment) is $0.360,0.244$, and 0.188 , respectively. We can infer that students intend to use MBA if it is useful to them primarily, then if it is easy to use, and finally, if it is enjoyable. This means that extrinsic motivation factors (e.g. usefulness, and ease of use) are more motivational for students than intrinsic motivation factors (e.g. Enjoyment) to use an MBA . Content is considered as a vital key to accept the mobile-based assessment. This is illustrated by significant impacts on students' usefulness, ease of use, and enjoyment. Moreover, this has been confirmed by standard estimation results of the revised model which are illustrated in estimation column in Table 1.8, where content has a more significant effect on student' usefulness (0.403), then on ease of use (0.315), and finally, on enjoyment (0.237). According to this result, students intend to use an MBA if the content of the MBA is useful to them primarily, then if it is easy to use, and finally, if it is enjoyable. It can be suggested that the content of an assessment must be useful to students by reflecting the content of the course as much as possible. Also, the simplicity of an assessment is essential, through using the closed answer questions instead of open answer questions. Besides, the assessment must carry challenges to motivate students to challenge themselves. These are vital considerations in facilitating the improvement of the learners' intention to use MBA.

A navigation system also plays a vital role in the students' intent to use MBA that can make significant impacts on students' ease of use, and students' enjoyment. Moreover, this has been confirmed by standard estimation results of the revised model which are illustrated in estimation column in table 1.8, where navigation has a more significant effect on students' enjoyment (0.628), then on ease of use (0.288). According to this result, students intend to use an MBA if the navigation of the MBA is enjoyable to them primarily, then if it is easy to use. It can be suggested that the providers of mobile-based assessment, must take into account the userfriendliness of a navigation system, by enabling students to navigate smoothly without any limitations in the MBA system. These are vital enhancements in facilitating the improvement in the learners' sense of fun in using MBA.

\section{Limitations}

This study is limited in several ways. Firstly, the study only relied on a sample size of 90 . Thus, there is a limitation concerning getting an adequate and representative sample for the study. A sample size of 90 may not be sufficient to generalize on the study population. Besides, the ideal population of interest should comprise participants from other public universities and various disciplines, not only one university (Tafila Technical University). The participants for this study are from the computer science and mathematics departments. Students from other disciplines are not included. Therefore, the data collected for this study cannot be guaranteed as comprehensive and accurate. Another weakness is the use of a quasi-experiment and self-reported MBA questionnaire. Responses from self-reported questions may not be entirely accurate, due to lack of self-awareness in answering the items in the questionnaire correctly, or because of a partial understanding of the study. The restriction of the data collection devises to smartphones iOS, and Android reduced the number of participants. As mentioned earlier, the study population should comprise all students of higher learning institutions in Jordan. Nevertheless, due to the researcher's inability to cover a large number of individuals within the time and financial limits, the population of the study was restricted to students in only one public university in Jordan who voluntarily participated in the research. There is, therefore, the possibility that the responses of the students varied in specific aspect from that a larger population would provide. Previous literatures claimed that the construct that accounts for technology acceptance is complex and that the direct correlation between navigation, content ad intention to use must be determined. This research adopts a non-direct relationship between navigation, content and intention to use MBA. There may be other models, which can capture both direct and indirect relationship between content, navigation and intention to use MBA.

\section{RECOMMENDATIONS}

Several recommendations can be given from the conclusion of this study. There is no doubt that more studies are required to widen the current findings. Since MBA is still new to the Jordanian education framework, it is therefore suggested that further studies are carried out in this area to enhance flexible education and MBA. This will trigger the use of MBA in the new era of teaching and learning. In this research, all the respondents were undergraduate (IT students) from a higher learning institution in Jordan. It is suggested that future studies should include postgraduates and students from other disciplines in the samples. Besides, the study population can be expanded to include additional higher learning institutions to strengthen the power of making inferences and generalizability of the findings. With regards to methodology, it is suggested that a longitudinal design is applied in future researches.

\section{CONCLUSION}

MBA is a new medium of evaluating teaching and learning in the modern educational landscape. The assessment can cover a large number of students with ease and with a high level of precision for real-time feedback and interactive tools. This study adds a new dimension to the existing literature on technology acceptance in teaching and learning. The research model, based on technology acceptance, 
was proposed and evaluated with data collected from university students. This study produces an adequate structural model using path analysis. The results demonstrate a healthy and positive relationship between the predictors and criterion variables. Perceived usefulness, perceived ease of use and perceived enjoyment significantly and positively affect the intent to use MBA. Perceived ease of use is observed to positively affect the perceived usefulness of mobile-based assessment. Content is observed to positively affect the perceived usefulness, perceived ease of use and perceived enjoyment of mobile-based assessment. Navigation significantly and positively affects the perceived ease of use and perceived enjoyment of mobile-based assessment. A significant correlation is also found between navigation and content of the mobile-based assessment. The study conclusion supports previous findings that good content, easy navigation, perceived usefulness, perceived ease of use and perceived enjoyment, increase students' intention to accept the mobile-based assessment. It can be concluded that the proposed model supports students' intention to use mobile-based assessment, especially for students in institutions of higher learning.

\section{APPENDEX}

Instrument Items

\begin{tabular}{|c|c|c|}
\hline 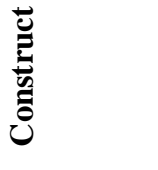 & $\stackrel{\Xi}{\Xi}$ & 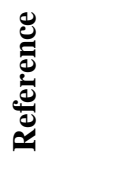 \\
\hline \multirow[t]{4}{*}{ Content } & $\begin{array}{l}\text { MBA questions were clear } \\
\text { and understandable. }\end{array}$ & \multirow{4}{*}{$\begin{array}{l}\text { Nikou } \\
\text { and } \\
\text { Econom } \\
\text { ide } \\
(2017)\end{array}$} \\
\hline & $\begin{array}{l}\text { MBA questions were relative } \\
\text { with the course syllabus }\end{array}$ & \\
\hline & $\begin{array}{l}\text { MBA questions were useful } \\
\text { for my course }\end{array}$ & \\
\hline & $\begin{array}{l}\text { MBA questions were } \\
\text { challenging }\end{array}$ & \\
\hline \multirow[t]{4}{*}{ Navigation } & $\begin{array}{l}\text { MBA allows navigation } \\
\text { through the assessment } \\
\text { environment }\end{array}$ & \multirow[t]{4}{*}{$\begin{array}{l}\text { Cheng, } \\
\text { Y. M. } \\
(2015)\end{array}$} \\
\hline & $\begin{array}{l}\text { Navigation through the MBA } \\
\text { is easy }\end{array}$ & \\
\hline & $\begin{array}{l}\text { Navigation allows me to move } \\
\text { fluidly through the MBA }\end{array}$ & \\
\hline & $\begin{array}{l}\text { MBA allows flexibility in } \\
\text { tracking down questions }\end{array}$ & \\
\hline $\begin{array}{l}\text { Ease of } \\
\text { Use }\end{array}$ & $\begin{array}{l}\text { My interaction with MBA is } \\
\text { clear and understandable }\end{array}$ & $\begin{array}{l}\text { Davis } \\
(1989)\end{array}$ \\
\hline
\end{tabular}

\begin{tabular}{|c|c|c|}
\hline 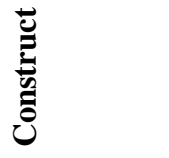 & $\stackrel{\Xi}{巳 ٍ \Xi}$ & 递 \\
\hline & $\begin{array}{l}\text { It is easy for me to become } \\
\text { skilful at using MBA. }\end{array}$ & \\
\hline & $\begin{array}{l}\text { I find the MBA system easy } \\
\text { to use }\end{array}$ & \\
\hline \multirow[t]{3}{*}{ Usefulness } & $\begin{array}{l}\text { Using MBA enhances my } \\
\text { effectiveness. }\end{array}$ & \multirow[t]{3}{*}{$\begin{array}{l}\text { Davis } \\
(1989)\end{array}$} \\
\hline & MBA is useful for my study. & \\
\hline & $\begin{array}{l}\text { Using MBA increases my } \\
\text { productivity. }\end{array}$ & \\
\hline \multirow[t]{4}{*}{ Enjoyment } & MBA is entertaining & \multirow{4}{*}{$\begin{array}{c}\text { Davis et } \\
\text { al. } \\
(1992) \\
\text { Lee et } \\
\text { al. } \\
(2005)\end{array}$} \\
\hline & MBA is exciting & \\
\hline & MBA is pleasant & \\
\hline & Overall, I enjoy using MBA & \\
\hline \multirow[t]{3}{*}{$\begin{array}{l}\text { Intention to } \\
\text { Use }\end{array}$} & $\begin{array}{l}\text { I indent to use MBA in the } \\
\text { future }\end{array}$ & \multirow[t]{3}{*}{$\begin{array}{c}\text { Davis } \\
(1989)\end{array}$} \\
\hline & $\begin{array}{l}\text { I plan to use MBA in the } \\
\text { future. }\end{array}$ & \\
\hline & $\begin{array}{l}\text { I predict I would use MBA in } \\
\text { the future }\end{array}$ & \\
\hline
\end{tabular}

\section{REFERENCES}

1. Nikou, S. A., \& Economides, A. A. (2017 a). MobileBased Assessment: Integrating acceptance and motivational factors into a combined model of SelfDetermination Theory and Technology Acceptance. Computers in Human Behavior, 68, 83-95. https://doi.org/10.1016/j.chb.2016.11.020

2. Nikou, S. A., \& Economides, A. A. (2017 b). Mobilebased assessment: Investigating the factors that influence behavioral intention to use. Computers \& Education, 109, 56-73.

3. Nikou, S. A., \& Economides, A. A. (2014, November). A model for MBA adoption based on SelfDetermination Theory of Motivation. In Interactive Mobile Communication Technologies and Learning (IMCL), 2014 International Conference on (pp. 86-90). IEEE.

https://doi.org/10.1109/IMCTL.2014.7011111

4. Ozdamli, F. (2012). Pedagogical framework of mlearning. Procedia-Social and Behavioral Sciences, 31, 927-931.

5. Nikou, S. A., \& Economides, A. A. (2015, November). The effects of perceived mobility and satisfaction on the adoption of mobile-based Assessment. In Interactive Mobile Communication Technologies and Learning (IMCL), 2015 International Conference on (pp. 167-171). IEEE.

6. Nikou, S. A., \& Economides, A. A. (2016). An outdoor MBA activity: Measuring students' motivation and acceptance. International Journal of Interactive Mobile Technologies, 10(4), 11-17.

7. Nikou, S. A., \& Economides, A. A. (2018). Mobilebased assessment: A literature review of 
publications in major referred journals from 2009 to 2018. Computers \& Education, $125,101-119$. https://doi.org/10.1016/j.compedu.2018.06.006

8. F. D. Davis. "Perceived usefulness, perceived ease of use and useracceptance of information technology". MIS Quartely, vol. 13, no. 3, pp.319-340, 1989.

9. Y. Liu, S. Han, \& H. Li. "Understanding the factors driving m-learning adoption: a literature review". Campus-Wide Information Systems, vol.27, no. 4, pp. 210-226, 2010.

https://doi.org/10.1108/10650741011073761

10. S.Y. Park, M.-W. Nam, \& S.-B. Cha. "University students' behavioral intention to use mobile learning: Evaluating the technology acceptance model". British Journal of Educational Technology, vol. 43, no. 4, pp.592-605, 2012.

11. K. F. Hashim, F. B. Tan, \& A. Rashid. "Adult learners' intention to adopt mobile learning: A motivational perspective". British Journal of Educational Technology, 2014. Retrieved 06 June 2014.

12. Chou, P. N., Chang, C. C., \& Lin, C. H. (2017). BYOD or not: A comparison of two assessment strategies for student learning. Computers in Human Behavior, 74, 63-71.

https://doi.org/10.1016/j.chb.2017.04.024

13. Dalby, D., \& Swan, M. (2019). Using digital technology to enhance formative assessment in mathematics classrooms. British Journal of Educational Technology, 50(2), 832-845. https://doi.org/10.1111/bjet.12606

14. Kuo-Hung, C., Kuo-En, C., Chung-Hsien, L., Kinshuk, \& Yao-Ting, S. (2016). Integration of mobile AR technology in performance assessment. Journal of Educational Technology \& Society, 19(4), 239-251.

15. Al-Emran, M., Elsherif, H. M., \& Shaalan, K. (2016). Investigating attitudes towards the use of mobile learning in higher education. Computers in Human Behavior, 56, 93-102. https://doi.org/10.1016/j.chb.2015.11.033

16. Venkatesh, V., Thong, J. Y., \& Xu, X. (2012). Consumer acceptance and use of information technology: extending the unified theory of acceptance and use of technology. MIS quarterly, 36(1), 157-178. https://doi.org/10.2307/41410412

17. Almaiah, M. A., \& Al Mulhem, A. (2019). Analysis of the essential factors affecting of intention to use of mobile learning applications: A comparison between universities adopters and non-adopters. Education and Information Technologies, 24(2), 1433-1468.

18. Alshehri, M., Drew, S., Alhussain, T., \& Alghamdi, R. (2012). The Effects of Website Quality on Adoption of E-Government Service: AnEmpirical Study Applying UTAUT Model Using SEM. arXiv preprint arXiv:1211.2410.

19. Rodrigues, G., Sarabdeen, J., \& Balasubramanian, S. (2016). Factors that influence consumer adoption of e-government services in the UAE: A UTAUT model perspective. Journal of Internet Commerce, 15(1), 1839.

20. Park, E., Baek, S., Ohm, J., \& Chang, H. J. (2014). Determinants of player acceptance of mobile social network games: An application of extended technology acceptance model. Telematics and Informatics, 31(1), 3-15.

https://doi.org/10.1016/j.tele.2013.07.001

21. Liu, Y., \& Li, H. (2011). Exploring the impact of use context on mobile hedonic services adoption: An empirical study on mobile gaming in China. Computers in Human Behavior, 27(2), 890-898.

22. Kim, B., Choi, M., \& Han, I. (2009). User behaviors toward mobile data services: The role of perceived fee and prior experience. Expert Systems with Applications, 36(4), 8528-8536. https://doi.org/10.1016/j.eswa.2008.10.063

23. Ha, I., Yoon, Y., \& Choi, M. (2007). Determinants of adoption of mobile games under mobile broadband wireless access environment. Information \& management, 44(3), 276-286.

24. Lee, M. K., Cheung, C. M., \& Chen, Z. (2005). Acceptance of Internet-based learning medium: the role of extrinsic and intrinsic motivation. Information \& management, 42(8), 1095-1104.

25. Van der Heijden, H. (2004). User acceptance of hedonic information systems. MIS quarterly, 695-704.

26. Teo, T. S., Lim, V. K., \& Lai, R. Y. (1999). Intrinsic and extrinsic motivation in Internet usage. Omega, 27(1), 25-37.

27. Igbaria, M., Iivari, J., \& Maragahh, H. (1995). Why do individuals use computer technology? A Finnish case study. Information \& management, 29(5), 227238.

28. Davis, F. D., Bagozzi, R. P., \& Warshaw, P. R. (1992). Extrinsic and intrinsic motivation to use computers in the workplace 1. Journal of applied social psychology, 22(14), 1111-1132.

29. Briz-Ponce, L., Pereira, A., Carvalho, L., JuanesMéndez, J. A., \& García-Peñalvo, F. J. (2017). Learning with mobile technologies-Students' behavior. Computers in Human Behavior, 72, 612-620.

30. Mac Callum, K., \& Jeffrey, L. (2014). Comparing the role of ICT literacy and anxiety in the adoption of mobile learning. Computers in Human Behavior, 39, 8-19.

31. Abu-Al-Aish, A., \& Love, S. (2013). Factors influencing students' acceptance of m-learning: An investigation in higher education. The International Review of Research in Open and Distributed Learning, 14(5).

32. Park, S. Y., Nam, M. W., \& Cha, S. B. (2012). University students' behavioral intention to use mobile learning: Evaluating the technology acceptance model. British Journal of Educational Technology, 43(4), 592-605.

33. Terzis, V., \& Economides, A. A. (2011). The acceptance and use of computer-based assessment. Computers \& Education, 56(4), 1032-1044.

34. Bere, A. (2014, April). Exploring determinants for mobile learning user acceptance and use: An application of UTAUT. In Information Technology: New Generations (ITNG), 2014 11th International Conference on (pp. 84-90). IEEE. https://doi.org/10.1109/ITNG.2014.114

35. Sánchez-Prieto, J. C., Olmos-Migueláñez, S., \& GarcíaPeñalvo, F. J. (2016). Informal tools in formal 
contexts: Development of a model to assess the acceptance of mobile technologies among teachers. Computers in Human Behavior, 55, 519-528.

36. Poong, Y. S., Yamaguchi, S., \& Takada, J. I. (2017). Investigating the drivers of mobile learning acceptance among young adults in the World Heritage town of Luang Prabang, Laos. Information Development, 33(1), 57-71. https://doi.org/10.1177/0266666916638136

37. Childers, T. L., Carr, C. L., Peck, J., \& Carson, S. (2001). Hedonic and utilitarian motivations for online retail shopping behavior. Journal of retailing, 77(4), 511-535.

38. Hoffman, D. L., \& Novak, T. P. (1996). Marketing in hypermedia computer-mediated environments: Conceptual foundations. Journal of marketing, 60(3), 50-68.

39. Tucker, S. P. (2008). E-commerce standard user interface: an E-menu system. Industrial Management \& Data Systems, 108(8), 1009-1028.

40. Avellis, G., Scaramuzzi, A., \& Finkelstein, A. (2004). Evaluating non-functional requirements in mobile learning contents and multimedia educational software. Learning with mobile devices: Research and development. London: Learning and Skills Development Agency.

41. Lee, Y. E., \& Benbasat, I. (2003). Interface design for mobile commerce. Communications of the ACM, 46(12), 48-52. https://doi.org/10.1145/953460.953487

42. Khalifa, M., \& Ning Shen, K. (2008). Explaining the adoption of transactional B2C mobile commerce. Journal of enterprise information management, 21(2), 110-124.

43. Cheng, Y. M. (2015). Towards an understanding of the factors affecting m-learning acceptance: Roles of technological characteristics and compatibility. Asia Pacific Management Review, 20(3), 109-119.

44. Mullen, E. M. (1995). Mullen scales of early learning (pp. 58-64). Circle Pines, MN: AGS.

45. Sperber, A. D., Devellis, R. F., \& Boehlecke, B. (1994). Cross-cultural translation: methodology and validation. Journal of cross-cultural psychology, 25(4), 501-524. https://doi.org/10.1177/0022022194254006

46. Hair, A. (1998). Tatham, and Black. Análisis multivariante.

47. Holmes-Smith, P. (2001). Introduction to structural equation modeling using LISREL. ACSPRI-Winter training program, Perth.

48. Wang, J., \& Wang, X. (2012). Structural equation modeling: Methods and applications. Wiley.

49. Bagozzi, R. P., \& Yi, Y. (1988). On the evaluation of structural equation models. Journal of the academy of marketing science, 16(1), 74-94.

https://doi.org/10.1007/BF02723327

50. Bentler, P. M., \& Bonett, D. G. (1980). Significance tests and goodness of fit in the analysis of covariance structures. Psychological bulletin, 88(3), 588.

51. Byrne, B. M. (2001). Structural equation modeling with AMOS, EQS, and LISREL: Comparative approaches to testing for the factorial validity of a measuring instrument. International journal of testing, 1(1), 55-86.

52. Cheng, Y. M. (2015). Towards an understanding of the factors affecting m-learning acceptance: Roles of technological characteristics and compatibility. Asia Pacific Management Review, 20(3), 109-119.

53. Zhang, J., Chang, C., \& Zhou, P. (2015, October). Factors affecting the acceptance of mobile devices in the classroom. In 2015 International Conference of Educational Innovation through Technology (EITT) (pp. 294-298). IEEE. https://doi.org/10.1109/EITT.2015.67

54. Wang, Y. S., Wu, M. C., \& Wang, H. Y. (2009). Investigating the determinants and age and gender differences in the acceptance of mobile learning. British journal of educational technology, 40(1), 92-118.

55. Almaiah, M. A., Alamri, M. M., \& Al-Rahmi, W. (2019). Applying the UTAUT Model to Explain the Students' Acceptance of Mobile Learning System in Higher Education. IEEE Access, 7, 174673-174686.

56. Almaiah, M. A., \& Alyoussef, I. Y. (2019). Analysis of the Effect of Course Design, Course Content Support, Course Assessment and Instructor Characteristics on the Actual Use of E-Learning System. IEEE Access, 7, 171907-171922.

57. Almaiah, M. A., \& Al-Khasawneh, A. Investigating the main determinants of mobile cloud computing adoption in university campus. Education and Information Technologies, 1-21.

58. Almaiah, M. A., Jalil, M. A., \& Man, M. (2016). Extending the TAM to examine the effects of quality features on mobile learning acceptance. Journal of Computers in Education, 3(4), 453-485. https://doi.org/10.1007/s40692-016-0074-1

59. Almaiah, M. A., \& Man, M. (2016). Empirical investigation to explore factors that achieve high quality of mobile learning system based on students' perspectives. Engineering science and technology, an international journal, 19(3), 1314-1320.

60. Almaiah, M. A., \& Alismaiel, O. A. (2019). Examination of factors influencing the use of mobile learning system: An empirical study. Education and Information Technologies, 24(1), 885-909.

61. Almaiah, M. A., Alamri, M. M., \& Al-Rahmi, W. M. (2019). Analysis the effect of different factors on the development of Mobile learning applications at different stages of usage. IEEE Access, 8, 1613916154.

62. Almaiah, M. A., \& Al Mulhem, A. (2019). Analysis of the essential factors affecting of intention to use of mobile learning applications: A comparison between universities adopters and non-adopters. Education and Information Technologies, 24(2), 1433-14 https://doi.org/10.1007/s10639-018-9840-1

63. AZEEZ, N. D., \& LAKULU, M. M. (2018). EVALUATION FRAMEWORK OF MGOVERNMENT SERVICES SUCCESS IN MALAYSIA. Journal of Theoretical and Applied Information Technology, 96(24). 